\title{
Four Butterflies: End of Life Stories of Transition and Transformation
}

\author{
Marcia Brennan
}

(C) Springer Science+Business Media, LLC 2012

\begin{abstract}
In this article, the author discusses her experiences as an Artist In Residence in the Department of Palliative Care and Rehabilitation Medicine at the University of Texas M. D. Anderson Cancer Center. Emphasis is placed on the ways in which end of life images and narratives often unfold in the fragile yet powerful space where conceptions of aesthetics and spirituality intersect with critical issues in the medical humanities. Drawing on four vivid case studies, the author examines the ways in which end of life narratives shed valuable light on conceptions of the subtlety of human embodiment; issues of violation, sorrow, and forgiveness; the mystical dimensions of traditional cultural beliefs; and the capacity for perceiving the natural world as a living symbol of grace. In so doing, she explores how the themes of transition and transformation become invested with meaningful existential and symbolic dimensions in artworks that give voice and presence to some of the most vulnerable, and often invisible, members of our society-people at the end of life.
\end{abstract}

Keywords Palliative medicine $\cdot$ Medical humanities $\cdot$ End of life $\cdot$ Aesthetics $\cdot$ Spirituality

\section{Introduction: artists in residence: creation and connection}

At its heart, the concept of social justice holds the promise of fostering meaningful change, change that can move us beyond established social forms, thus promoting a sense of "metamorphosis." Such transitions and transformations can be realized through an expansion of perspective that recognizes the dignity and value of each human being, and that acknowledges the ways in which unique experiences powerfully inform accompanying modes of knowledge and representation. While the project of social justice can, and does, take many different forms, in this article I will focus on some specific techniques through which we can give voice, image, and presence to some of the most vulnerable, marginalized, and often invisible members of our society—namely, people at the end of life.

M. Brennan $(\bowtie)$

Department of Religious Studies, MS 15, Rice University, Box 1892, Houston, TX 77251-1892, USA

e-mail: mbrennan@rice.edu 
The four narratives that appear below - our four butterflies of transformation - have much to teach us about conceptions of the subtlety of human embodiment; issues of violation, sorrow, and forgiveness; the mystical dimensions of traditional cultural beliefs; and the capacity for perceiving the natural world as a living symbol of grace. While each of the narratives is deeply rooted in vivid details drawn from personal life experiences, the stories also carry a powerful social resonance as they encourage us to consider the integration and translation of moving humanistic perspectives into clinical practices, while simultaneously promoting broader cultural awareness of life at the end of life. In so doing, the stories engage not only issues of social justice, but of what it might mean to do justice to the social, particularly when we find ourselves facing subjects and situations that we often have so much trouble bringing ourselves to look at.

Since early 2009, it has been my privilege to serve as an Artist In Residence in the Department of Palliative Care and Rehabilitation Medicine at the University of Texas M. D. Anderson Cancer Center. No matter how many times I pass through the hospital doors, I always feel like I'm walking on sacred ground. In my mind's eye, I often see a trail of rose petals forming a pathway into the hospital building, onto the Acute Palliative Care Unit, and into the patients' rooms. Sitting quietly with each person, listening closely to their stories through conversations that range across a broad emotional and existential spectrum, the etheric rose petals often appear to change color before my eyes.

In my "day job," I am a modernist art historian at Rice University, where my research areas include modern and contemporary art history and museum studies, comparative religion and mysticism, and the emerging field of the medical humanities. Despite their significant differences, each of these projects shares a common set of themes and challenges, namely: How do we find language to describe states of being for which there is no language? How do we represent the unrepresentable and translate the untranslatable? Notably, these questions are as pertinent to theoretical discussions of abstract painting's simultaneously dissolving and crystallizing structures as they are to the contemplation of spiritual experience and mystical ecstasy, as they are to the very real challenges of people at the end of life. Thus throughout all of my work I am fascinated - and profoundly moved - by subjects and situations that repeatedly exceed our capacity to represent them, even as we repeatedly attempt to do so, often through imagery that conveys transitional states and transformational visions.

At M. D. Anderson, I collaborate closely with another Artist In Residence, the nationally distinguished painter Lynn Randolph. Our work is facilitated by COLLAGE: The Art for Cancer Network, a non-profit organization founded by Dr. Jennifer Wheler, Assistant Professor in Investigational Cancer Therapeutics. On the ward, our work is supported by Dr. Eduardo Bruera, Professor of Medicine and F. T. McGraw Chair in the Treatment of Cancer, who generously endorses COLLAGE's mission and provides a pilot site for the Artist In Residence program. Working together, Lynn and I assist patients and their caregivers in creating meaningful texts and images to express their insights and experiences. Most of the people that Lynn and I encounter are not well enough to produce art with their own hands. Thus we primarily serve as translators, yet much of what we translate is ineffable. We create a context, and provide critical skills, so that people facing extraordinarily difficult life situations have an opportunity for personal and symbolic expression, which then becomes clothed in visual and literary forms.

As artists, Lynn and I constantly confront the challenge of creating human connections across a formidable gulf of separation. Frequently, when we initially approach a patient, we 
are told that the work "sounds interesting, but I have no artistic ability." This invites us to respond, "Well, let's just say for a moment that you did have artistic ability. What images would you want to paint or write?" Depending on the circumstances, we might also ask, "What do you love to do?" or more simply, "What do you love?" Very often a flash of illumination will become visible on the person's face, and they will share an image with us. They will often describe a scene that Lynn will help them create visually, while I gently encourage them to talk and make notes to help crystallize their thoughts. Once the artwork is complete, I read the person's words back to them. The image and the narrative are then inscribed into a handmade paper journal, which the person is able to keep and share with their family. In this way, the portable microenvironment of the text provides a durable yet tender memory of this transient moment in their lives.

It is my experience that, perhaps above all else, people at the end of life are seeking acknowledgement and affirmation of their thoughts, their feelings, their stories, and their presences. The artist's physical and etheric nod of the head gives the person proof of one energetic touch, as they bring forth the psychological and spiritual dimensions of life, love, and illness. As this suggests, the end of life can be an exceptionally powerful time of transition and transformation on the physical, emotional, intellectual, and spiritual levels. Working at the bedside and the chairside, I have repeatedly observed that some individuals describe a deep sense of mystical communion with the natural world, while others express profound spiritual insights through established religious themes and traditions. Notably, because this work unfolds in Houston, Christian themes tend to recur in the end of life narratives; however, the production of the artworks could extend to any faith tradition, even as the work does not have to include a religious component at all. Despite their significant differences, the themes of transition and transformation run like golden threads through the four stories I'm about to share with you.

\section{The two bodies that are one body}

One day on the ward we encountered an African American woman who requested a picture of her nude, cancer-scarred body, an image that she wanted to share with her family, her friends, and the members of her church. She removed her hospital gown and assumed a recumbent pose on the bed that resembled the classic reclining posture of the artist's model, yet which also displayed unfamiliar elements including an implantable port and taped plastic tubing. This woman was clear that the drawing should not include her face, but should focus instead on her body as a universal symbol of humanity, "so that when God brings me up to heaven, it will be an incentive for others to see the power." Throughout our visit this woman cited various biblical verses, including Proverbs 15:29: "[God] heareth the prayer of the righteous"; James 5:16: "The effectual fervent prayer of a righteous man availeth much"; and Psalm 139:14: "I will praise thee, for I am fearfully and wonderfully made. Marvelous are thy works, and that my soul knoweth right well."1 While Lynn made a sensitive pencil drawing as a legacy gift for this woman and her family, I listened closely to her story and inscribed her narrative on a sheet of thick, cream-colored paper:

\footnotetext{
${ }^{1}$ This woman's story also resonates thematically with the discussion of the resurrection of the body found in 1 Corinthians 15. However, the biblical text makes a clear distinction between the "earthly" or "natural" body that is composed of mortal flesh and the "heavenly" or "spiritual" body that is "imperishable." In contrast, the two aspects of embodiment - the corporeal and the spiritual — become conflated in this woman's vision.
} 
The Two Bodies That Are One Body

I feel like I have two different bodies.

This is because of how my body looks now.

I've lost so much weight.

I have one body here on earth,

And one body there in heaven.

This is how it looks now.

But in time, I'm going to gain back my strength.

It looks like two bodies to the physical eye,

But it's still only one body.

This is something I've learned since I got sick.

I am wonderfully made,

And God doesn't make mistakes.

I know it, and I want others to know it.

No matter how things look,

God's righteousness avails much.

God hears the prayers of the righteous.

I pray this will help somebody.

I've asked God to use me as a vessel,

To show people how powerful He is,

And the work He can do.

And if this draws souls to Him,

Then so be it.

The two bodies are still one body.

While this woman's stated purpose in making the image was deeply tied to her Christian faith, her powerful words and gesture expressed a thematics of incarnational theology that were located within, yet which also transcended, the boundaries of any orthodox religious structure. As such, this artwork incorporates a paradox of duality and nonduality, as conveyed through a sense of being fragmented yet unified, vulnerable yet powerful, finite yet infinite, mortal yet immortal, two and yet one. Thus when engaging this text and image, viewers simultaneously encounter not one body but two, as the artwork gives voice and presence to powerful conceptions of multiplicity and transformation at both the existential and symbolic levels. ${ }^{2}$

\section{For goodness sake}

On another afternoon, the last patient we saw was an elderly African American man who was all alone in his room and eager to visit with us. Generously calling our visit a gift, he

\footnotetext{
${ }^{2}$ From a Gender Studies perspective, these artworks raise a number of complex questions that lie beyond the scope of this article, yet which deserve to be identified. Namely, death occurs within the context of a life, and given that lives are gendered, so too are elements of a person's passing, particularly concerning issues of corporeality, identity, and memory. Yet do end of life narratives shed meaningful light on whether men and women die differently? Does death represent a state beyond gender? Moreover, what are the methodological implications and the ideological stakes in raising such questions, and how might we begin to formulate an epistemology that could accommodate such an inquiry?
} 
immediately responded to us, and he broke down in tears several times during the visit. Sometimes he covered his eyes with a paper napkin, as though he could not bear to look at us, or for us to see him. He told us, "My God has been so good to me, with the gifts and blessings he's given me." He also told us about his daughter, about how much he loved her, and how hard she had worked, and how she had carried all the burdens of burying the relatives. Then he looked us straight in the eye and said, "Ladies, I won't lie to you. I got out of prison last year. I came out in a wheelchair." Following his release, he had been doing fine for a little while, but then he became "deathly ill" and had to be admitted to the hospital. He suffered from stage four metastatic prostate cancer that had spread to his bones. When he complained of back pain in prison, he was shrugged off, and told that the pain came from standing on concrete floors for so many years. Since "every prisoner has a complaint," he was ignored until it was too late and treatment was no longer an option. Again, the tears started to flow as he closed his eyes and said, "Ladies, I won't lie to you. I've been the murderer, the robber, the rapist, and the thief. I'm guilty of way more than anything they convicted me for. I spent so many long calendar years in prison. I had been locked up for a couple of years, and I found my loving God." He described his experiences with the prison ministry and he then remarked that, if this hospital room were hell, there would be one corner where people were doing one set of things, and one corner where they were doing another, and then he pointed to the far corner of the room by the door and said that he would be in that corner: "I' $\mathrm{d}$ rather be among those who are sitting there, trying to pray their way up, then those sitting there, accepting their fate. I'd rather be with those who tried to pray their way out of hell." Lynn made a colored pencil portrait of this man on his knees in hell surrounded by a circle of fiery flames, while praying his way up to heaven, with a golden halo encircling his head. His story is entitled:

\section{"For Goodness Sake"}

Those were my Grandmother's words,

And she used to say to me,

"Boy, do this for goodness sake,

For the sake of goodness."

I didn't get the meaning of that until a year ago,

When I got out of prison.

I was locked up for so many long calendar years.

When I had been locked up for a couple of years,

I found my Loving God.

In prison, I prayed,

"Please God, let my child forgive me."

Two weeks later,

My daughter came to prison.

She is such a special child.

She stood at the table.

Out of the clear blue sky, she said,

"Daddy, I forgive you.

I forgive you with the full measure

That I want to be forgiven for my sins."

She came back and verbalized

The prayer,

As I had said it.

And then I knew what it meant 
To do something purely for the sake of Goodness,

For Goodness Sake.

And then I knew that there was

A God in Heaven.

After I read this man his story, he cried again because he said that his daughter's words were exactly as I had spoken them. In these extraordinary circumstances, the artist performs a type of witness function, a critical affirmation in which people tell us their stories so that there can be a surfacing to consciousness of something that is lying just below the conscious level. In particular, this story relates to the searing pain of hell on earth and heartfelt prayers for forgiveness. I have found that such hell surfaces when there is great physical, emotional, or spiritual pain, which can come from an overwhelming sense of fear, anger, guilt, loneliness, struggle, or lack of acceptance (du Boulay 1985; Saunders 1995). Clearly, this man was in a place of profound suffering and uncertainty, and he was seeking forgiveness and release through the conscious affirmation that his words had been heard and his prayer had been answered (Capps and Carlin 2010). Two days after sharing this story of transition and transformation, this man passed away peacefully at M. D. Anderson.

\section{The gift of the traditional ways}

Very often with Palliative Care patients, biographical themes and natural imagery merge with dreams and symbols, as individual experience becomes intertwined with collective sacrality and visionary consciousness. These interwoven strands thread through the iconographically and cosmologically intricate narrative of a Native American woman, as elements of earth, air, and fire became infused with accompanying sacred associations in her Native traditions. When we first met this woman, she had less than a month to live. She informed the medical staff that she was eager to work with the artists, because she wanted to construct images based on her cherished heritage. During our visit, this woman spoke to us in a low, soft, rapid voice as one set of memories and metaphors flowed into the next. Closely following her stream of words, Lynn made a symbolic portrait of this woman with her face positioned at the center of a dream catcher that trailed behind her at an angle with feathers encircling its outer edges, "as though catching her soul." The woman's face appeared against the backdrop of her own rising heart, which floated in the sky and was flanked by a group of wolves, which represented her family's clan symbol. Her composite portrait levitated above, yet was connected to, a slender cord of etheric clouds and glowing flames that linked her presence to an eternal fire burning on the ground below. While Lynn translated these terrestrial and celestial elements into a detailed colored pencil portrait, I recorded the woman's words in a story entitled:

The Gift Of The Traditional Ways: It's Very Rare, Around The Heart

I am full-blooded Native American,

And I'd like to have an image of a dream catcher,

A rectangular shape,

A medium-sized web

That goes out at an angle

And catches people's dreams.

When my time eventually does come, 
I'd like to have a dream catcher on my casket.

I'm of the Wolf Clan on my mother's side.

That's my heritage.

In our culture,

When I grew up,

We had a Never Ending Fire,

A fire that was never allowed to go out.

That's our background.

I'm very drawn to the color blue, to medium blue.

I think of the dream catcher

Going out at an angle,

With wolves standing at the sides

And a moon at the top.

The sky is a blue hue, medium blue,

And the wolves are looking through

The dream catcher.

I've been told that people think

I'm a Shaman.

I get knowings, and I have premonitions.

I just know things,

And I don't know how I know them.

I just do.

I have cancer in the fluid around my heart,

Which is very rare.

What I've gone through is just another learning lesson

For me to help other people.

If I live,

I would use my powers to help others.

I've never understood it,

But I've always had the gift

Of the traditional ways.

It's very rare,

Around the heart.

\section{Like a butterfly, for His glory}

Our final story also draws on natural imagery to evoke powerful conceptions of transition and transformation, themes that thread through a woman's personal life experiences and which relate to her Christian faith. Yet while the stories I've recounted so far center on people of color who have faced extremely challenging life circumstances, the final narrative is located in a decidedly different subject position. One day Lynn and I met an older couple in which the wife had just been admitted to the Palliative Care Inpatient Unit. This couple was obviously extremely close, and we soon learned that they would be married for nearly 
half a century. While this woman had devoted her life to being a wife and mother, her husband had enjoyed an extremely successful professional career. Even now, while clothed modestly in a hospital gown, this woman retained an elegant appearance and she still wore some of her diamond jewelry. When we asked her what she loved, she quickly responded, "I love God and Jesus above everything else. I taught Bible School for some twenty-odd years. I found God as a young child and I was always devout, but the cancer has made me even more so." As our conversation unfolded we learned that, in addition to her love for her church and family, this woman also loved butterflies. Indeed, these fragile creatures were sacred to her and played an important role at transitional moments in her life. Lynn drew a delicate colored pencil portrait of this woman encircled by butterflies, which appeared as fluttering clouds of color, while a single butterfly perched lightly on her shoulder. The story is entitled:

\section{Like A Butterfly, For His Glory}

I love God above everything,

And I love my family,

And anything having to do with nature.

Since I was diagnosed with cancer,

I've had a lot of experiences with butterflies.

My daughter was with me,

And she had to go back home.

It was early December-and pretty cool outside-

And there weren't many butterflies around.

But one day she called me on the phone and said,

"Mom, I'm sitting here, feeling really sad,

And my friend who was sitting there beside me said, 'Look down!'”

And there was a gorgeous yellow butterfly

Sitting on her salad.

It flew away,

And then - that one, or another - came back and landed.

I knew that God was talking to us.

He can take something ugly,

And make it beautiful.

My daughter knew the first butterfly was for me,

And the second one was for her.

When we were coming home after the first chemo trip,

I stopped the car and got out.

No sooner had I taken a few steps,

But a huge yellow swallowtail encircled us,

And it was saying, "Welcome Home!"

God was encircling us,

And it was just wonderful.

Another time, I was just sitting there,

Feeling depressed.

I couldn't move my legs.

And all of a sudden, 
A gorgeous, light orange butterfly came up.

She landed there,

And she stayed for at least half an hour.

Every time I've needed a lift,

Or needed God's presence,

There's a butterfly there.

If God can take this ugly, fuzzy old thing

And turn it into something beautiful-

Like a butterfly-

Then God can take this ugly cancer

And make something beautiful

For His Glory.

He can, and He does.

The butterflies are like a sunset,

All for His Glory.

\section{Some closing thoughts on aesthetic transformations}

The four stories that appear in this essay-our four butterflies of transformation - are perhaps somewhat unexpected in an article focusing on end of life narratives produced through clinical encounters with terminal cancer patients (Brayne 2010; Charon 2006; Fenwick and Fenwick 2008; Stanworth 2004). Indeed, the phrase "end of life" evokes a dark side of our cultural landscape, which ranges from highly politicized, ideologicallyinflected specters of "death panels" (Gawande 2010) to mainstream journalistic accounts of cancer as a kind of living death of unspeakable pain, in which individual case histories are described as ongoing battles in an exhausting war with long odds against an aggressively powerful enemy (Kolata 2009). In short, the language deployed is grim, terrifying, and dispiriting, as people are portrayed as robbed of their humanity. This is consistent with our predominant cultural approach to cancer, which privileges evidencebased medicine and a science of "objective truth" that has, at once, blinded us to ugliness (through the oversaturation of dehumanizing mass cultural imagery) and blinded us to beauty (through the underrepresentation of a moving humanism).

In contrast, the end of life narratives that appear in this essay exemplify the ways in which artistic expressions can offer valuable complements to both the limits and the possibilities of biomedicine in the face of suffering, uncertainty, and the search for meaning often associated with death (Kübler-Ross 1969; Mitford 1998). Indeed, these complex materials instantiate a dimension of the medical humanities that unites direct clinical experiences with moving humanistic, aesthetic, and spiritual elements. Moreover, this work reflects the capacity of aesthetics to promote an integrated epistemological approach that conjoins an existential, experiential base with the vivid power of the creative imagination, the rigor of intellectual and philosophical reflection, and an evocative sense of spirituality that can express the sacred and the ineffable.

By engaging these subjects, this project also raises key questions regarding the possibilities and the limits of representation and unrepresentability. Working in a 
palliative care context, I have repeatedly found that the artworks we produce together embody an extremely beautiful and difficult paradox, as the uniqueness of the person will always be evoked by-yet will always transcend-the particular details of the words and images that we record (Derrida 2008). Time and again, this paradox of simultaneous inscription and supersession becomes not only evident, but vividly intense, when approaching life at the end of life. This paradox, in turn, becomes reflected in both the poetic form and the affective content of the representations themselves, as well as in the delicate materials in which they are inscribed. This is particularly the case given that the handmade paper journals provide an ethereal yet tangible product during a time when life and language are slipping away. Thus both formally and iconographically, the artworks are inherently fragile, evanescent, and provisional, and in their very finitude they symbolically embody a presence that will always exceed the capacities of language and representation. Moreover, it is precisely because the acknowledgement of their fragmentary nature is built into the character of the artworks, a corresponding sense of boundedness and boundlessness, of limitations and their simultaneous transcendence, appear not as familiar categorical dualisms, but as complementary propositions as one mode of expression continually opens ontoand heightens - the other.

Put another way, the work of the Artist In Residence unfolds in the space where the life of the mind meets the life of the heart in light of the practice. From this inclusive location, the artworks form a composite perspective that promises to move us beyond the conventional boundaries that demarcate stable categorical distinctions between representation and unrepresentability, presence and transcendence, and "beauty" and "ugliness," thereby productively complicating the relationship between ethics and aesthetics. In so doing, the artworks shed valuable light on an extremely difficult and often overlooked subject that nonetheless remains an integral part of our individual human experience and our collective social condition, while potentially fostering transformation through vivid images of transformation.

\section{Publication note}

This article is drawn from my forthcoming book, Words Beyond Words: Finding Language Where There Is No Language, which will be published by Intellect Books (U.K. and the University of Chicago Press). This project has been favorably reviewed by two independent Institutional Review Boards (IRBs) at Rice University and at the M. D. Anderson Cancer Center. Notably, the subjects of this transdisciplinary project are universal, human, and deeply important; as such, they raise a host of compelling issues regarding subjectivity, sensitivity, visibility, representation, and compassion that must be processed within our culture. At the same time, due to privacy concerns, the narratives presented here are abstracted sketches that are intended to be generic and anonymous. Particular details relating to specific individuals have been omitted or altered, thereby assuring HIPPA compliance and preserving issues of confidentiality, particularly as specified under "The Privacy Rule," The Belmont Report, and the Department of Health and Human Services Office for Human Research Protections, including The Common Rule and subparts B, C, and D of the Health and Human Service specifications as outlined in the Code of Federal Regulations (CFR) at 45 CFR 164 and 165, which specifies the "safe harbor" method of de-identification. 
Acknowledgments My heartfelt thanks go to Dr. Eduardo Bruera and Dr. Jennifer Wheler for their generosity and support; to Lynn Randolph for her work as an artistic collaborator; to Tom Cole for his insightful comments and incisive questions; and to Nate Carlin for his kindness and enthusiasm in inviting me to participate in the "Social Justice and the Health Professions" conference that he co-organized at the McGovern Center for Humanities and Ethics, University of Texas Health Science Center (June 2, 2011).

\section{References}

Brayne, S. (2010). The D- word: talking about dying: a guide for relatives, friends, and carers. London: Continuum.

Capps, D., \& Carlin, N. (2010). Living in limbo: life in the midst of uncertainty. Eugene: Cascade.

Charon, R. (2006). Narrative medicine: honoring the stories of illness. New York: Oxford University Press. Derrida, J. (2008). The gift of death. Trans. David Willis. Chicago: University of Chicago Press.

du Boulay, S. (1985). Changing the face of death: the story of Cicely Saunders. Norfolk.: Religious and Moral Education Press.

Fenwick, P., \& Fenwick, E. (2008). The art of dying: a journey to elsewhere. London: Continuum.

Gawande, A. (2010). Letting go: what should medicine do when it can't save your life? The New Yorker. http://www.newyorker.com/reporting/2010/08/02/100802fa_fact_gawande.

Kolata, G. (2009). A place where cancer is the norm. New York Times. http://www.nytimes.com/2009/10/25/ health/research/25anderson.html?pagewanted=all.

Kübler-Ross, E. (1969). On death and dying. New York: Scribner.

Mitford, J. (1998). The American way of death revisited. New York: Vintage Books.

Saunders, C. (1995). Living with dying: a guide to palliative care. Oxford: Oxford University Press.

Stanworth, R. (2004). Recognizing spiritual needs in people who are dying. Oxford: Oxford University Press. 